\section{Women celebrate successful campaign
on gender issues}

Women's groups attending the World Conference on Science were opening the champagne on Wednesday night (30 June) as news began to leak to them from the committee drafting the final conference documents that they had been successful in significantly enhancing all references to the need to improve the position of women in science.

There had earlier been warnings that women and women's issues might be marginalized. But after a determined campaign and the final adoption of the Declaration and Framework for Action (see opposite), female participants in the conference were unanimous in their enthusiastic approval of the final version of the two documents.

"It is the first time that [the gender issue] has entered the world science agenda," says Sjamsiah Achmad, of the Indonesian Institute of Technology, in Jakarta, who had chaired the conference's 'thematic session' on gender-related issues. "We managed to get a whole new paragraph inserted into the Framework for Action. It is extraordinary."

Wati Hermawati, another member of the Indonesian delegation, says she will produce gender indicators, through her work for the National Focal Point for Gender Science and Technology at the same institute. Statistics and data will be collected in areas such as the education and careers of women in science, and the impact of science and technology on women.

Amalia Bosia, a molecular biologist from the University of Turin and a member of the Italian delegation, says that the final documents adopted by the meeting appear to have taken into account some of the views expressed to Unesco and ICSU during the preparatory process. These included declarations from seven regional forums that had looked at the issue of women in science. "Some of the things that went in [to the documents] may be obvious, but the important thing is that they came from a general opinion," says Bosia.

The success of the women's lobby at the conference was the result of a campaign that started more than a year ago, when representatives of the UN Development Fund for Women (UNIFEM) and the Once and Again Future Action Network (OFAN) decided that the conference was important.

These groups formed a gender networking group at the conference. The group lobbied non-governmental organizations, placed representatives in thematic meetings, analysed lists of delegates for gender bias, and even noted down the number of times that gender was mentioned during the plenary sessions. Full text: http://helix.nature.com/wcs/1news/02-1d.html

\title{
Declaration the 'backbone' for cooperation in Africa
}

Research ministers from 50 African states are planning to meet in Cairo next January under the auspices of the Organization of African Unity (OAU) to discuss drawing up a protocol for scientific collaboration across the continent.

Such a protocol, which it is hoped will be signed by heads of state, could represent one of the more concrete follow-up activities to make use of the guidelines for promoting science in the interests of development agreed at the World Conference on Science.

The ideas enshrined in the declaration agreed at the Budapest meeting are likely to provide the "backbone" to such an agreement, says Henri Hogbe Nlend, minister for science and technology in Cameroon. Nlend, who will chair the Cairo meeting, describes it as an "African projection" of the conclusions of the world conference.

Nlend describes the conference as having been successful, partly because many of the ideas that African delegations had been keen to promote - such as that of science being "part of the common heritage of mankind" - were recognized in the conclusions.

Like others, he would have liked to have seen additional points included in the final declarations, such as explicit support for the need to increase funding for science. He points out that the last such meeting, in Vienna in 1979, endorsed a target of spending one per cent of gross national product on research.

"A figure like that creates a target by which we can measure our efforts," he says. "You can then tell governments that the money they allocate to science is too small in comparison to what other countries are spending."

\section{US proposes focus on science teaching}

The United States, currently considering the terms of a potential bid to rejoin Unesco, has suggested that the organization should consider "resurrecting" a previously successful division of science education within its education sector.

The suggestion came in a statement to the plenary session of the World Conference on Science by Michael Southwick, US deputy assistant secretary of state, who described the Budapest meeting as "Unesco at its best".

The United States withdrew from the organization in the mid-1980s over complaints of maladministration and overpoliticization. A proposal last year from the State Department to ask Congress for funds to rejoin was shelved after discussions with

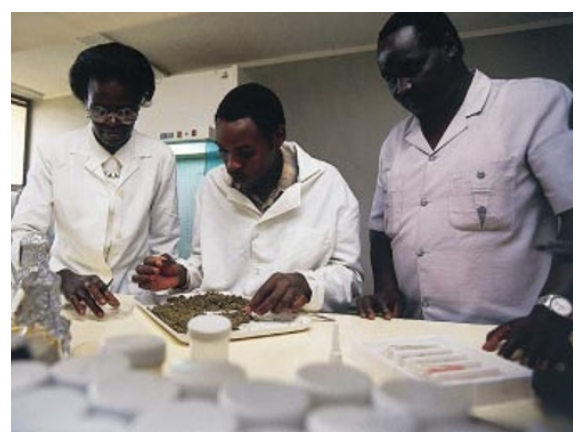

Research collaboration: African protocol would put conference principles into practice.

But Nlend says he is pleased that the final declaration acknowledges the need for new funding mechanisms at national and regional levels. "There is a strong appeal to increase money for science and technology" he says. "Any new mechanism that is launched does not have to be a global fund."

Nlend says he is also pleased that the responsibility for follow-up activities has been broadened, allowing regional organizations (such as the OAU) to take up the challenge. He is less happy with those parts of the declaration that deal with intellectual property rights. He feels that the declaration skirts around issues raised by the privatization of research, for example in health provision.

"Such fields are more and more controlled by multinational corporations," says Nlend. "Delegates have spoken about the dangers of this, and the issue has been referred to in the final documents, but the wording is not strong enough." the Office of Management and Budget concluded that the timing was premature.

Southwick pointed out that there had been a time when the education sector had had an "extraordinarily active and effective" division of science education. "Might it be time to resurrect it?"

His remarks reflected strong feelings about the need to boost science education worldwide held by members of the US delegation, including Bruce Alberts, president of the National Academy of Sciences, and Leon Lederman, former director of the Fermi National Laboratory.

Lederman said scientists needed to communicate the importance of nurturing scientific literacy in schools.

Full text: http://helix.nature.com/wos/1news/02-1i.htm 